\title{
Treating Mixed Astigmatism - A Theoretical Comparison and Guideline for Combined Ablation Strategies and Wavefront Ablation
}

\author{
Diego de Ortueta ${ }^{1}$, Samuel Arba Mosquera ${ }^{2}$ and Christoph Haecker ${ }^{3}$ \\ ${ }^{1}$ Medical Director Augenlaserzentrum Recklinghausen, \\ Consultant AURELIOS Augenzentrum, \\ ${ }^{2}$ Schwind Eye-Tech Solutions, Kleinhostheim \\ ${ }^{3}$ Independent Physiscist \\ Germany
}

\section{Introduction}

The goal of laser refractive surgery is to achieve predictable and stable correction of myopia, hyperopia, and astigmatism. New, sophisticated diagnostic instruments such as topographers and aberrometers offer potential for improved results in terms of treatment efficiency and visual quality.( MaRae $t$ al. 2000, Seiler et al. 2000, Manns et al. 2002, Mrochen et al. 2004)

Many articles have been published concerning laser correction of myopia and hyperopia with and without astigmatism, but few dealing with mixed astigmatism (Chayet et al 1998, Chayet et al 2001, Hasabla et al. 2003, Albarran-Diego et al. 2004, De Ortueta\&Haecker 2008, Stonecipher et al. 2010). In the late 90's Chayet (Chayet et al 1998, Chayet et al 2001), and Vinciguerra (Vincinguerra et al. 1999) published toric ablation techniques, which apply a myopic cylinder and a hyperopic cylinder (90 degrees away).

Azar (Azar\&Primack 2000) and Gatinel (Gatinel et al. 2002) compared the theoretical ablation profiles and depths of tissue removal for all kinds of astigmatism using various ablation strategies such as combined hyperopic spherical and myopic cylindrical treatments, combined spherical (plus or minus) and hyperopic cylindrical treatments, combined cylindrical treatments, and combined Cross-Cylinder and spherical equivalent (SEQ) treatments.

Both authors concluded that combined spherical and hyperopic cylindrical or combined cylindrical approaches result in reduced ablation depth for treating compound hyperopic and mixed astigmatism whereas applying a hyperopic sphere combined with a myopic cylinder incurs the largest amount of central and peripheral corneal tissue ablation. (Azar\&Primack 2000) Despite these important theoretical publications, the definitions and differences between Bitoric and Cross-Cylinder treatments remain unclear in various publications. (Hasaballa et al. 2003, Gatinel et al 2002, Doane\&Slade 2003) .

For this reason, we attempt to provide a guideline for refractive surgeons including a subclassification of mixed astigmatism and a generalised Bitoric formula. Furthermore, we compare and contrast Bitoric, Cross-Cylinder and combined spherical and cylindrical 
(Sequential) ablation strategies with $2^{\text {nd }}$ order wavefront ablation for the correction of mixed astigmatism. We want to know which ablation strategie uses less ablation depht. In order to compare our results with the findings of Azar (Azar\&Primack 2000) and Gatinel (Gatinel et al. 2002) we expand the theoretical comparison by pure myopic and hyperopic as well as compound myopic and hyperopic astigmatism. For treating mixed astigmatism we differentiate between cases of zero or negative spherical equivalent (SEQ $\leq 0 \mathrm{D})$ and positive SEQ.

\section{Materials and methods}

\subsection{Sub-classification of mixed astigmatism}

Optically the spherical equivalent (SEQ) of an astigmatic eye represents the circle of least confusion (conoid of Sturm), which has two main focal lines, each one parallel to one of the principal meridians of a spherocylindrical lens (American Academy Ophthalmology 20022003) The location of these focal lines leads to the classification of astigmatism:

- Simple or pure astigmatism: one focal line is on the retina

- Compound myopic astigmatism: both focal lines are in front of the retina

- Compound hyperopic astigmatism: both focal lines are behind the retina

- Mixed astigmatism: one focal line is in front of the retina and one is behind the retina

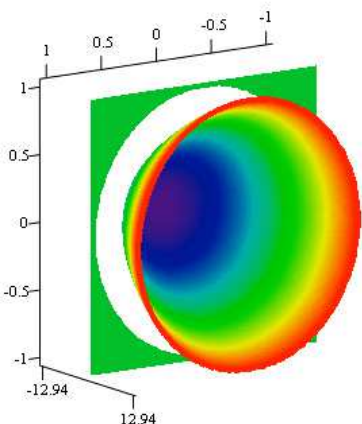

W1

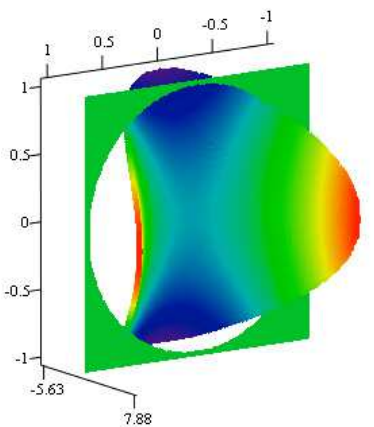

W4

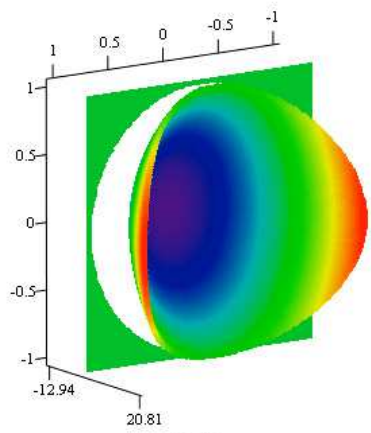

W2

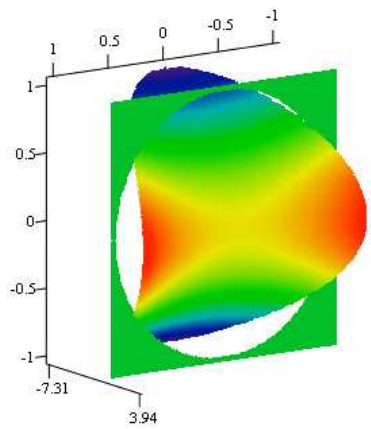

W5
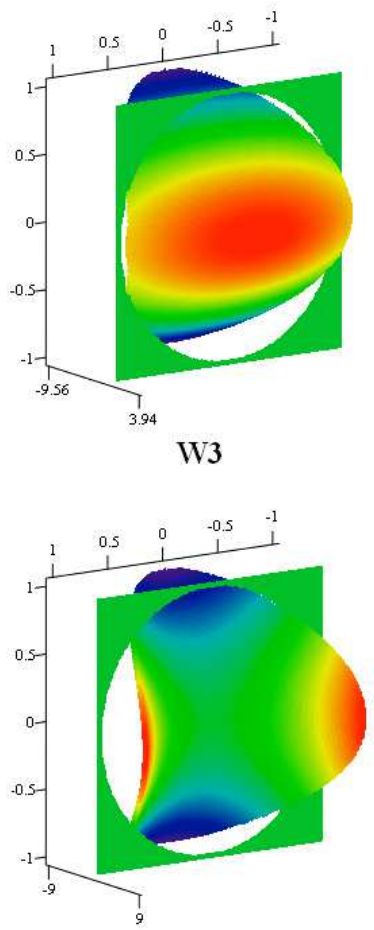

W6

Fig. 1. Three-dimensional $2^{\text {nd }}$ order wave front maps 
Three dimensional wavefront maps illustrate the circle of least confusion in reference to the retina and help to sub-classify mixed astigmatism. Figure 1 represents outgoing $2^{\text {nd }}$ order wavefront maps over the exit pupil plane. The green frame surrounding the wavefront maps indicates an aberration-free plane wavefront. For a purely myopic eye (W1, figure1) the optical path is shorter for rays passing near the pupil margin compared to rays passing through the pupil center (chief ray) (Thibos\&Applegate 2001). Hence, the back reflected wavefront arrives earlier in the periphery (red color) compared to the chief ray (center of the pupil), indicated by the blue color. Unlike the regular bowl shaped pattern of W1 the wavefront error of myopic astigmatism (W2) indicates two concave meridians of different radii. For hyperopic astigmatism (W3) rays of light in the periphery travel a longer distance compared to the chief ray (red area), which is represented by the convex shaped wavefront map. In contrast to previous maps mixed astigmatism, represented by W4, W5 and W6 (Figure 1), indicates that the cross section along one principle meridian is concave whereas the other meridian is curved convex.

The centre (blue colour) of wavefront map W4 $(+1.00-3.00 \times 180$, SEQ $=-0.50 \mathrm{D})$ is located behind the green frame, indicating a myopic eye, whereas the central yellow colour of W5 $(+2.00-2.50 \times 180, \mathrm{SEQ}=0.75 \mathrm{D})$ represents a hyperopic eye. Wavefront map W6 (Figure 1) depicts mixed astigmatism $(+2.00-4.00 \times 180)$ with a SEQ of $0.00 \mathrm{D}$. Hence, the conoid of Sturm is in the retinal plane (the centre of the map has the same colour as the surrounding green frame). In summary, whether using minus or plus cylinder convention, mixed astigmatism can be sub-characterised into:

a. Mixed astigmatism of SEQ $<0$ (myopic) W4

b. Mixed astigmatism of SEQ $>0$ (hyperopic) W5

c. Mixed astigmatism of SEQ $=0$ (emmetropic) W6

\subsection{Bitoric versus cross-cylinder}

In general, Arturo Chayet (Chayet et al. 2001) and Paolo Vinciguerra (Vincinguerra et al. 1999) describe methods to split the prescription into two cylindrical (toric) ablation patterns: applying a minus cylinder to flatten the steep meridian and a plus cylinder (90 degrees away) to steepen the flat meridian. The two authors have differing concepts. A major difference between the two concepts is the proportion used to "split" the spherocylindrical prescription. The Cross-Cylinder approach (P.Vinciguerra) proposes a three-stage treatment. The prescribed subjective cylinder (figure 2) is split into two halves $\mathrm{C}_{\text {neg }}$ (negative cylinder) and $\mathrm{C}_{\text {pos }}$ (positive cylinder) of equal magnitude and opposite sign (Figure 2). Where the initial prescription has a minus cylinder convention, the positive cylinder is treated at 90 degrees to the negative cylinder. As a third step the residual refractive error is compensated by a spherical treatment.

In contrast to the Cross-Cylinder approach, the Bitoric concept of Chayet (Chayet et al. 2001) proposes a two-stage treatment: Splitting the cylinder into two perpendicular components of opposite sign and differing magnitude. Additionally, Chayet's concept considers a compensation for the coupling effect (hyperopic shift) which occurs when a myopic cylinder is treated (Chayet et al 1998, Chayet et al 2001, McDonell 1991)

The original Bitoric formula (figure 3), published by Chayet (Chayet et al. 2001) is used with prescriptions in minus cylinder convention. It was designed for Nidek Excimer lasers with a coupling effect of approximately 33\%, which is an empirical factor based on clinical experience with the $\mathrm{Nidek}^{\circledR}$ laser. 


$$
\begin{aligned}
& \text { (1) } \mathrm{SEQ}=\mathrm{S}_{\text {subj }}+0.5 \cdot \mathrm{C}_{\text {subj }} \\
& \text { (2) } \mathrm{C}_{\text {neg }}=0.5 \cdot \mathrm{C}_{\text {subj }} \\
& \text { (3) } \mathrm{C}_{\text {pos }}=0.5 \cdot\left|\mathrm{C}_{\text {subj }}\right| \\
& \begin{array}{ll}
\mathrm{SEQ} \text { : spherical equivalent } & \mathrm{C}_{\text {neg }} \text { : negative cylinder } \\
\mathrm{C}_{\text {pos }} \text { : positive cylinder } & \mathrm{S}_{\text {subj }} \text { : subjective sphere }
\end{array} \\
& \mathrm{C}_{\text {subj }} \text { : subjective cylinder } \\
& \text { Example: }+\mathbf{1 . 5 0}-\mathbf{5 . 0 0} \times 180 \\
& \mathrm{SEQ}=1.5 \mathrm{D}+0.5 \cdot(-5 \mathrm{D})=-1 \\
& \mathrm{C}_{\text {neg }}=0.5 \cdot(-5 \mathrm{D})=-2.50 \times 180 \\
& \mathrm{C}_{\text {pos }}=0.5 \cdot 5 \mathrm{D}=+2.50 \times 90
\end{aligned}
$$

Fig. 2. Cross-Cylinder formula (Vinciguerra)

Furthermore, it might be confusing that the result always becomes a positive figure (example, figure 3) although a negative cylinder will be applied. For these reasons, we developed a general Bitoric formula for individual Excimer laser systems, provided in Figure 4. It may be used for both, minus and plus cylinder convention. However, it is important to apply the correct axis for each cylinder. Considering minus cylinder convention, the negative cylinder will be applied according to the axis of the prescription. The plus cylinder is treated at 90 degrees to the negative cylinder. Considering plus cylinder convention, the positive cylinder is treated according to the axis of the prescription and the negative cylinder is treated at $90^{\circ}$ to the positive cylinder.

$$
\begin{aligned}
& \text { (4) } \mathrm{C}_{\text {neg }}=\left|\mathrm{S}_{\text {subj }}+\mathrm{C}_{\text {subj }}\right| / 1.33 \\
& \text { (5) } \mathrm{C}_{\text {pos }}=\left|\mathrm{C}_{\text {subj }}\right|-\mathrm{C}_{\text {neg }} \\
& \mathrm{C}_{\text {neg }}: \text { negative cylinder } \quad \mathrm{C}_{\text {pos }}: \text { positive cylinder } \\
& \mathrm{S}_{\text {subj }}: \text { subjective sphere } \quad \mathrm{C}_{\text {subj }}: \text { subjective cylinder } \\
& \text { Example: }+\mathbf{1 . 5 0}-\mathbf{5 . 0 0} \times \mathbf{1 8 0} \\
& \mathrm{C}_{\text {neg }}=3.5 \mathrm{D} / 1.33=+2.63 \times 180 \\
& \mathrm{C}_{\text {pos }}=5 \mathrm{D}-2.63 \mathrm{D}=+2.37 \times 90
\end{aligned}
$$

Fig. 3. Original Bitoric formula (Chayet) showing a coupling factor of $33 \%$ which is the specifically for the Nidek laser.

\subsection{Sequential method}

Another approach to correction of mixed or compound astigmatism is to treat spherical and cylindrical components sequentially (Sequential method) as prescribed (minus or plus 


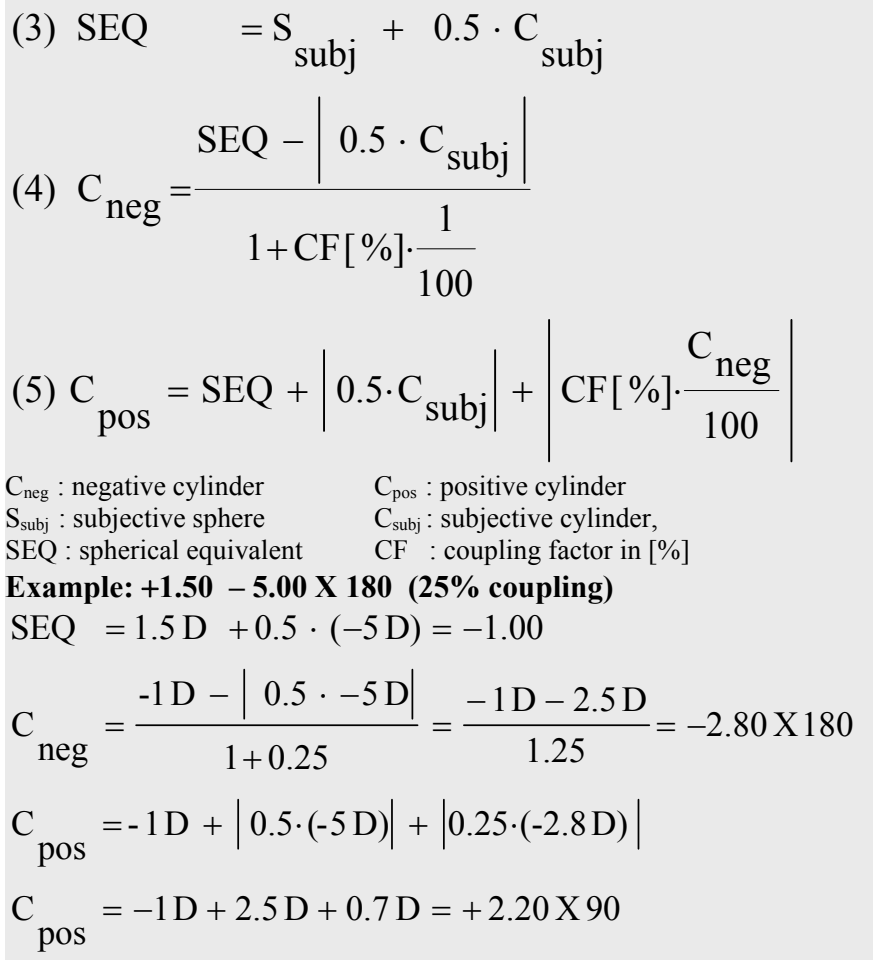

Fig. 4. General Bitoric formula

cylinder convention). For example the prescription of $+1.00-3.00 \times 90$ would be corrected by combining a hyperopic sphere of $+1.00 \mathrm{D}$ with a myopic cylinder of $-3.00 \times 90$ or after converting to plus cylinder convention $(-2.00+3.00 X 180)$ as follows: $-2.00 \mathrm{D}$ sphere combined with a hyperopic cylinder of $+3.00 \times 180$.

\subsection{Wavefront ablation ( $2^{\text {nd }}$ order)}

Traditionally combined ablation strategies are used to correct the refractive error with LASIK, LASEK or PRK by means of additive optical correction. Hence, the overall correction is achieved by sequentially ablating spherical and/or cylindrical lenticules.

Since the introduction of wavefront analysis and Zernike decomposition, the refractive error of an eye may be described in terms of deviations from an ideal plane wavefront. Unlike traditional concepts, the opposed wavefront can directly correct these so-called aberrations on the cornea with a single step ablation.

In this study, MathCAD2000 Professional ${ }^{\circledR}$ is used to calculate and visualize ablation patterns for different ablation concepts. According to Mrochen et al. ${ }^{4}$ Zernike coefficients $Z$ $[2,0]$ (defocus), Z $[2,-2]$ and $Z[2,+2]$ (astigmatism) are derived from sphere (S), cylinder (C) and axis $(A)$ in order to describe $2^{\text {nd }}$ order wavefront errors $W(x, y)$ (Formula 6).

$$
W(x, y)=Z[2,-2] \cdot(2 x \cdot y)+Z[2,0] \cdot\left[2 \cdot\left(x^{2}+y^{2}\right)-1\right]+Z[2,+2] \cdot\left(x^{2}-y^{2}\right)
$$


After sign reversal of the wavefront error $W(x, y)$ further factors have to be taken into account to allow for the correction on the cornea (Equation 7): removing one micron of corneal tissue reduces the wavefront retardation by the difference of the refractive indices $\left(\mathrm{n}_{\text {stroma }}-\mathrm{n}_{\text {air }}\right)$. Secondly, because no tissue can be added onto the cornea $\mathrm{W}(\mathrm{x}, \mathrm{y})$ has to be shifted by the smallest constant $\mathrm{C}$ to keep the ablation $\mathrm{A}(\mathrm{x}, \mathrm{y})$ from becoming negative anywhere: (Huang 2001)

$$
\mathrm{A}(\mathrm{x}, \mathrm{y})=[\mathrm{C}-\mathrm{W}(\mathrm{x}, \mathrm{y})] \cdot\left[1 /\left(\mathrm{n}_{\text {stroma }}-\mathrm{n}_{\mathrm{air}}\right)\right]
$$

\subsection{Comparison of ablation strategies in terms of ablation depth}

For objective, theoretical comparison of different ablation strategies, it is necessary to neglect variables due to individual surgical techniques (e.g. nomogram adjustments). As well varying ablation profiles of different laser systems such as design of transition zone, coupling factors etc. must be excluded. High order aberrations (HOA) are excluded and optical zones (OZ) are kept constant at $6 \mathrm{~mm}$ for all calculations. Because we assume wavefront ablation to be the most direct way of refractive correction, it is chosen as the reference ablation volume for all examples.

To compare the traditional concepts with $2^{\text {nd }}$ order wavefront ablation, the spherocylindrical components of the combined ablation concepts (Bitoric, Cross-Cylinder and Sequential methods) are first derived from the subjective refraction. Then the wavefront error $W(x, y)$ for each spherocylindrical component (different for each concept) is transposed (huang 2001 ) into the corresponding ablation profile $A(x, y)$ (Equation 7$)$.

The total ablation for a combined ablation concept is calculated by adding (superimposing) its elementary optical components (Figure 5). Finally, the difference in shape and elevation is revealed by subtracting the $2^{\text {nd }}$ order wavefront ablation pattern (always considered as the reference) from the total ablation of the combined ablation concept.

\section{Results}

For simplicity, we illustrate with a single example (Figure 5) comparing the traditional ablation strategies with $2^{\text {nd }}$ order wavefront ablation. Further results for all ablation strategies and astigmatic corrections are shown in Table 1.

Using Bitoric ablation (Figure 5, first row) to correct mixed astigmatism (+3.00 -4.00 X 180) delivers positive Cylinder (PC1) (+3.00 X 90) and a negative cylinder (NC1) $(-1.00 \times 180)$. Superimposing PC1 and NC1 equates to TB1(total bitoric). The difference (DBW1) between total ablation (TB1) and wavefront ablation (WA) is DBW1 = TB1 - WA.

The Cross-Cylinder ablation (Figure 5, second row) suggests three steps: Sphere (S2 ) $(+1.00)$, positive cylinder (PC2) (+2.00 X 90) and negative cylinder (NC2) (-2.00 X 180). Subtracting TC2 (total ablation Cross-Cylinder) by the wavefront ablation equates to DCW2.

The sequential method in minus cylinder convention ablates corneal lenticules S3 $(+3.00)$ and NC3 (-4.00 X 180). The difference between sequential method (TSN3 = S3 + NC3) and wavefront ablation (WA) is represented by DSNW3 (Figure 5, third row). The sequential ablation in plus cylinder convention (Figure 5, last row) removes corneal lenticules S4 ($1.00)$ and PC4 (+4.00 X 90). The difference between the sequential method (TSP4 = S4 + PC4) and the wavefront ablation is represented by DSPW4. 


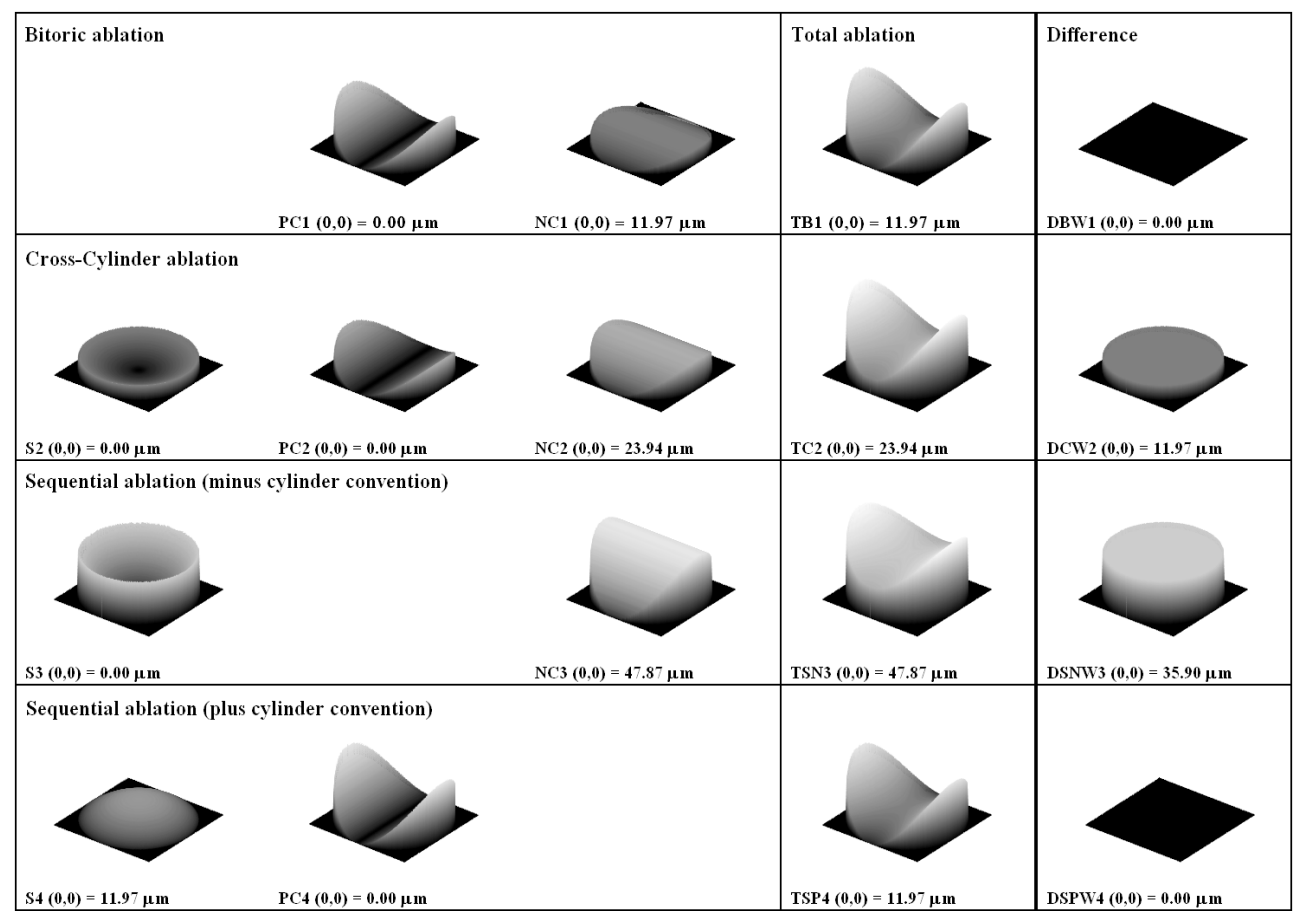

Fig. 5. Ablation strategies for "hyperopic" mixed astigmatism (+3.00 -4.00 X 180) PC (positive cylinder) , NC (negative cylinder), Total Bitoric (TBI), Total cross cylinder (TC), Total sphere and negative cylinder (TSN), Total sphere and positive cylinder (TSP), DB (difference to the Wavefront ablation)

For all methods, the right hand column of Figure 5 shows that the difference from $2^{\text {nd }}$ order wavefront profile is either zero or a layer of tissue of uniform thickness (PTK or piston).

Hence, the final geometric shape is identical for all approaches. For this reason, it is possible to compare the ablation depth of all approaches only in the ablation centre. Table 1 shows representative astigmatic corrections (in plus and minus cylinder convention) and their central ablation depths for different ablation concepts. Summarising the theoretical result for different astigmatic corrections yields a qualitative overview of differences in ablation depth for various ablation strategies:

\subsection{Pure myopic and pure hyperopic astigmatism}

For treating pure myopic astigmatism, all ablation strategies result in the same amount of tissue removal.

For pure hyperopic astigmatism, the Bitoric ablation is similar to wavefront ablation and the Sequential approach following the positive cylinder convention. The Cross-Cylinder technique ablates more tissue and the Sequential method applying a hyperopic sphere and a myopic cylinder ablates even more. 


\subsection{Compound myopic astigmatism}

Cross-Cylinder and both Sequential concepts are equal to wavefront ablation. Using the generalised Bitoric formula for myopic astigmatism leads to a special case of combining two crossed, myopic cylinders, which results in more tissue removal.

\subsection{Compound hyperopic astigmatism}

Bitoric ablation and the Sequential approach of treating a hyperopic sphere and a hyperopic cylinder are identical to Wavefront ablation. The Cross-Cylinder technique ablates more tissue and the Sequential method applying a hyperopic sphere and a myopic cylinder ablates even more.

\subsection{Mixed astigmatism (SEQ $\leq 0 \mathrm{D})$}

The least tissue removal to correct mixed astigmatism with a SEQ equal or less than 0 dioptres (SEQ $\leq 0 \mathrm{D}$ ) is achieved by Wavefront ablation, Bitoric, Cross-Cylinder and sequential treatment of myopic sphere and hyperopic cylinder. Sequential treatment of hyperopic sphere and myopic cylinder removes more tissue.

\begin{tabular}{|c|c|c|c|c|c|}
\hline $\begin{array}{l}\text { Ablation } \\
\text { concept }\end{array}$ & $\begin{array}{c}\text { prescription } \\
\text { [D] }\end{array}$ & $\begin{array}{c}\text { Wavefront } \\
\text { ablation } \\
\text { depth }\end{array}$ & $\begin{array}{c}\text { Bitoric } \\
\text { ablation } \\
\text { depth }\end{array}$ & $\begin{array}{l}\text { Cross- } \\
\text { Cylinder } \\
\text { ablation } \\
\text { depth }\end{array}$ & $\begin{array}{c}\text { Sequential } \\
\text { ablation } \\
\text { depth }\end{array}$ \\
\hline \multirow{2}{*}{$\begin{array}{l}\text { pure myopic } \\
\text { astigmatism }\end{array}$} & $0 /-4 \times 60$ & $47.9 \mu \mathrm{m}$ & $47.9 \mu \mathrm{m}$ & $47.9 \mu \mathrm{m}$ & $47.9 \mu \mathrm{m}$ \\
\hline & $-4 / 4 \times 150$ & $47.9 \mu \mathrm{m}$ & $47.9 \mu \mathrm{m}$ & $47.9 \mu \mathrm{m}$ & $47.9 \mu \mathrm{m}$ \\
\hline \multirow{2}{*}{$\begin{array}{l}\text { pure hyperopic } \\
\text { astigmatism }\end{array}$} & $3 /-3 \times 180$ & $0.0 \mu \mathrm{m}$ & $0.0 \mu \mathrm{m}$ & $18.0 \mu \mathrm{m}$ & $35.9 \mu \mathrm{m}$ \\
\hline & $0 / 3 \times 90$ & $0.0 \mu \mathrm{m}$ & $0.0 \mu \mathrm{m}$ & $18.0 \mu \mathrm{m}$ & $0.0 \mu \mathrm{m}$ \\
\hline \multirow{2}{*}{$\begin{array}{l}\text { comp. myopic } \\
\text { astigmatism }\end{array}$} & $-3 /-1 \times 90$ & $47.9 \mu \mathrm{m}$ & $83.8 \mu \mathrm{m}$ & $47.9 \mu \mathrm{m}$ & $47.9 \mu \mathrm{m}$ \\
\hline & $-4 / 1 \times 180$ & $47.9 \mu \mathrm{m}$ & $83.8 \mu \mathrm{m}$ & $47.9 \mu \mathrm{m}$ & $47.9 \mu \mathrm{m}$ \\
\hline \multirow{2}{*}{$\begin{array}{l}\text { comp. hyperopic } \\
\text { astigmatism }\end{array}$} & $4 /-2 \times 45$ & $0.0 \mu \mathrm{m}$ & $0.0 \mu \mathrm{m}$ & $12.0 \mu \mathrm{m}$ & $23.9 \mu \mathrm{m}$ \\
\hline & $2 / 2 \times 135$ & $0.0 \mu \mathrm{m}$ & $0.0 \mu \mathrm{m}$ & $12.0 \mu \mathrm{m}$ & $0.0 \mu \mathrm{m}$ \\
\hline \multirow[t]{2}{*}{$\begin{array}{l}\text { mixed astigmatism } \\
\text { SEQ }<0\end{array}$} & $1 /-3 \times 90$ & $23.9 \mu \mathrm{m}$ & $23.9 \mu \mathrm{m}$ & $23.9 \mu \mathrm{m}$ & $35.9 \mu \mathrm{m}$ \\
\hline & $-2 / 3 \times 180$ & $23.9 \mu \mathrm{m}$ & $23.9 \mu \mathrm{m}$ & $23.9 \mu \mathrm{m}$ & $23.9 \mu \mathrm{m}$ \\
\hline \multirow{2}{*}{$\begin{array}{l}\text { mixed astigmatism } \\
\qquad \mathrm{SEQ}=0\end{array}$} & $2 /-4 \times 60$ & $23.9 \mu \mathrm{m}$ & $23.9 \mu \mathrm{m}$ & $23.9 \mu \mathrm{m}$ & $47.9 \mu \mathrm{m}$ \\
\hline & $-2 / 4 \times 150$ & $23.9 \mu \mathrm{m}$ & $23.9 \mu \mathrm{m}$ & $23.9 \mu \mathrm{m}$ & $23.9 \mu \mathrm{m}$ \\
\hline \multirow[t]{2}{*}{$\begin{array}{l}\text { mixed astigmatism } \\
\qquad \mathrm{SEQ}>0\end{array}$} & $3 /-4 \times 45$ & $12.0 \mu \mathrm{m}$ & $12.0 \mu \mathrm{m}$ & $23.9 \mu \mathrm{m}$ & $47.9 \mu \mathrm{m}$ \\
\hline & $-1 / 4 \times 135$ & $12.0 \mu \mathrm{m}$ & $12.0 \mu \mathrm{m}$ & $23.9 \mu \mathrm{m}$ & $12.0 \mu \mathrm{m}$ \\
\hline
\end{tabular}

Table 1. Central ablation depths of astigmatic corrections for different ablation concepts 


\subsection{Mixed astigmatism (SEQ > 0 D)}

For "hyperopic" mixed astigmatism (SEQ > 0 D) Wavefront ablation, Bitoric ablation and the combination of myopic sphere and hyperopic cylinder equally remove least tissue. The Cross-Cylinder technique ablates more tissue and sequential treatment of hyperopic sphere and myopic cylinder ablates even more.

\section{Discussion}

We reaffirm that all correction strategies result in identical surface shape but differ in ablation depth. For treating astigmatism in general, $2^{\text {nd }}$ order wavefront ablation and Sequential treatment of spherical and hyperopic cylindrical lenticules are the most tissue saving methods. Hence, these strategies may likely be most efficient and most predictable in order to achieve the desired refractive and visual outcome. As removing less tissue makes the results more predictable and therefore more efficient.

In contrast to the findings of Gatinel (Gatinel et al. 2002) this study demonstrates that $2^{\text {nd }}$ order wavefront ablation results in minimum tissue removal, despite the fact of splitting the amount of astigmatism into 2 components (cardinal and oblique). In addition, we theoretically found that correction of mixed and compound hyperopic astigmatism using Bitoric ablation or using sequential ablation of spherical and hyperopic cylindrical components is identical to $2^{\text {nd }}$ order wavefront ablation.

While agreeing with Azar (Azar\&Primack 2000) and Gatinel (Gatinel et al 2002) that Vinciguerra`s cross-cylindrical approach for compound hyperopic and pure hyperopic astigmatism does not cause minimal tissue removal, our findings differ from those of Azar and Gatinel`s for mixed astigmatism. Using the Cross-Cylinder formula for mixed astigmatism with "hyperopic" SEQ removes more tissue, whereas in cases of zero or negative spherical equivalent $(\mathrm{SEQ} \leq 0 \mathrm{D})$ minimum amount of tissue is removed equally to Bitoric ablation, wavefront ablation and sequentially treating a sphere together with a hyperopic cylinder.

Bitoric and Cross-Cylinder (for SEQ $\leq 0$ D) ablations are appropriate methods to treat mixed astigmatism for Excimer lasers or software which do not allow $2^{\text {nd }}$ order wavefront based ablation or the combined treatment of myopic sphere and hyperopic cylinder. For treating mixed astigmatism Bitoric ablation has advantages compared to Cross-Cylinder ablation, because it accounts for the hyperopic shift, applies only 2 treatment steps and it results in minimal ablation depth. The Bitoric formula (Figure 4) should not be used for myopic astigmatism, because it applies two crossed minus cylinders resulting in excessive tissue removal. Except for pure myopic and compound myopic astigmatism, the sequential treatment of sphere and myopic cylinder should be avoided.

The intention of this paper is to reveal that ablation profiles based on $2^{\text {nd }}$ order Zernike polynomials lead to minimal tissue removal. However, ablation strategies, taking into account more variables (loss of efficiency, preoperative corneal asphericity, hyperopic shift etc.) might be the state-of-the-art technique to improve the visual outcome. Understanding the concept of wavefront ablation will lead to optimized photo-ablative standard treatments, especially when spherical aberrations are pre compensated for their induction. (Manns 2002) (Mrochen 2004) Then, in general the ablation depth will increase due to consideration of high order aberrations. 


\section{References}

Albarran-Diego C, Munoz G et al.(2004). Bitoric laser in situ keratomileusis for astigmatism. Journal of Cataract and Refractive Surgery, 30:1471-1478

American Academy Ophthalmology (2002-2003) Basic and Clinical Science Course, Section 3. Optics, refraction, and contact lenses, San Francisco: 87

Azar DT, Primack JD. (2000). Theoretical analysis of ablation depths and profiles in laser in situ keratomileusis for compound hyperopic and mixed astigmatism. Journal of Cataract and Refractive Surgery, 26:1123-1136

Chayet AS, Magallanes R, Montes M, et al. (1998). Laser in situ keratomileusis for simple myopic, mixed, and simple hyperopic astigmatism. Journal of Refractive Surgery, $14: 175-176$

Chayet AS, Montes M, Gómez L, et al. (2001). Bitoric laser in situ keratomileusis for the correction of simple myopic and mixed astigmatism. Ophthalmology, 108:303-308

De Ortueta D, Haecker C. (2008). Laser in situ keratomileusis for mixed astigmatism using a modified formula for bitoric ablation. European Journal of Ophthalmology 18(6):869-76

Doane JF, Slade SG. (2003) Treatment of Astigmatism. Custom Lasik: Surgical Techniques and Complications. Slack incorporated, 657-659

Gatinel D, Hoang-Xuan T, Azar DT. (2002). Three-dimensional representation and qualitative comparisons of the amount of tissue ablation to treat mixed and compound astigmatism. Journal of Cataract and Refractive Surgery;, 28:2026-2034

Hasaballa MA., Ayala MJ, Alío JL. (2003). Laser in situ keratomileusis correction of mixed astigmatism by bitoric ablation. Journal of Cataract and Refractive Surgery, 29: 1889-1895

Huang D. (2001). Physics of customized corneal ablation. Customized corneal Ablation: the quest for supervision. Slack incorporated, 51- 62

MacRae SM, Schwiegerling J, Snyder R (2000). Customized corneal ablation and super vision. Journal of Refractive Surgery, 16:230-235

Manns F, Ho A, Parel JM, Culbertson W (2002). Ablation profiles for wavefront-guided correction of myopia and primary spherical aberration. Journal of Cataract and Refractive Surgery, 28:766-774

McDonnel PJ, Moreira H, Garbus J, et al. (1991). Photorefractive keratectomy to create toric ablations for correction of astigmatism. Archives Ophthalmology 109:710-3

Mrochen M, Donitzky C, Wüllner C, Löffler (2004) J. Wavefront-optimized ablation profiles: Theoretical background. Journal of Cataract and Refractive Surgery, 30:775-785

Seiler T, Kaemmerer M, Mierdel P, Krinke HE (2000). Ocular optical aberrations after photorefractive keratectomy for myopia and myopic astigmatism. Archives Ophthalmology, 118:17-21

Stein R. (2003). Lasik for mixed Astigmatism. Custom Lasik: Surgical Techniques and Complications. Slack incorporated, 668-672

Stonecipher KG, Kezirian GM, Stonecipher K. (2010). LASIK for mixed astigmatism using the ALLEGRETTO WAVE: 3- and 6-month results with the 200- and 400-Hz platforms. Journal of Refractive Surgery., 26(10):S819-23

Thibos LN, Applegate RA. (2001) Assessment of optical quality. Customized corneal Ablation: the quest for supervision. Slack incorporated 67- 78

Vinciguerra P, Sborgia M, Epstein D, et al. (1999) Photorefractive keratectomy to correct myopic or hyperopic Astigmatism with a Cross-Cylinder ablation. Journal of Refractive Surgery , 15:183-18 


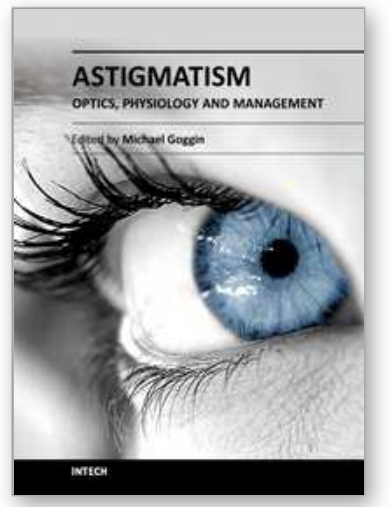

\author{
Astigmatism - Optics, Physiology and Management \\ Edited by Dr. Michael Goggin
}

ISBN 978-953-51-0230-4

Hard cover, 308 pages

Publisher InTech

Published online 29, February, 2012

Published in print edition February, 2012

This book explores the development, optics and physiology of astigmatism and places this knowledge in the context of modern management of this aspect of refractive error. It is written by, and aimed at, the astigmatism practitioner to assist in understanding astigmatism and its amelioration by optical and surgical techniques. It also addresses the integration of astigmatism management into the surgical approach to cataract and corneal disease including corneal transplantation.

\title{
How to reference
}

In order to correctly reference this scholarly work, feel free to copy and paste the following:

Diego de Ortueta, Samuel Arba Mosquera and Christoph Haecker (2012). Treating Mixed Astigmatism - A Theoretical Comparison and Guideline for Combined Ablation Strategies and Wavefront Ablation, Astigmatism - Optics, Physiology and Management, Dr. Michael Goggin (Ed.), ISBN: 978-953-51-0230-4, InTech, Available from: http://www.intechopen.com/books/astigmatism-optics-physiology-and-management/mixed-astigmatism

\section{INTECH}

open science | open minds

\section{InTech Europe}

University Campus STeP Ri

Slavka Krautzeka 83/A

51000 Rijeka, Croatia

Phone: +385 (51) 770447

Fax: +385 (51) 686166

www.intechopen.com

\section{InTech China}

Unit 405, Office Block, Hotel Equatorial Shanghai

No.65, Yan An Road (West), Shanghai, 200040, China

中国上海市延安西路65号上海国际贵都大饭店办公楼 405 单元

Phone: +86-21-62489820

Fax: $+86-21-62489821$ 
(C) 2012 The Author(s). Licensee IntechOpen. This is an open access article distributed under the terms of the Creative Commons Attribution 3.0 License, which permits unrestricted use, distribution, and reproduction in any medium, provided the original work is properly cited. 